\title{
Sobre el ministerio eclesial (I)
}

\section{José Ignacio González Faus, Facultad de Teología de Cataluña, Centro de Reflexión Teológica, San Salvador.}

\section{Introducción}

A pesar de su extensión $\longrightarrow$ precisamente por ella-, el presente artículo tiene muy pocas pretensiones de originalidad. $\mathrm{Ni}$ en lo exegético ni en lo histórico pretende afirmar nada que no sea ya conocido, y casi de dominio común 0 , al menos, suficientemente aceptado. Su única novedad podría estar en estas dos cosas: a) en el intento de poner juntos y unificar todos esos datos hoy aceptados, intento que varios han emprendido en más de una ocasión, con sistematizaciones y con acierto diversos; y b) en el objetivo que ha puesto en marcha ese afán sistematizador, y que sería el de aprender de la historia de la Iglesia, para nuestra labor misionera actual.

La acumulación de datos no se hace pues para alcanzar el saber, o la perfección académica (seguramente faltan muchos, unos por ignorancia mía y otros por la oblıgada selección que imponen las dimensiones de este escrito, aunque espero que los que aqui se recogen sean suficientes para justificar sus conclusiones). Pero sí quiero subrayar que el breve paseo por los datos aspira a iluminar la hora actual de la iglesia que $\rightarrow$ por lo que toca a nuestro tema — me parece marcada por estos tres grandes grupos de problemas.

1) La actual crisis del ministerio. Pienso que se da realmente esa crisis, y que es crisis de identidad. No me convence el argumento de quienes sostienen que la crisis del ministerio es un falso problema creado por la Iglesia al negarse a ordenar a hombres casados, y que bastaría con que la Iglesia diese ese paso para que desapareciera el problema. Independientemente de lo que haya que decir sobre esa cuestión, pienso que de poco valdría ordenar a hombres casados si no sabemos demasiado bien para qué se les ordena. Y que reducir ese "para-que," estereotipadamente, a la presidencia de la eucaristrá, acabara agudizando la crisis de sacramentalización que hoy experimentan muchos ministros, y reduciendo el minis- 
terio eclesial a un funcionariado, tan poco apetiloso sin celibato como con celibato.

En este sentido, muchas de las cosas que aquí digo, aunque pretenden brotar del Nuevo Testamento y de la historia de la Iglesia, forman parte de lo que ha querido ser más de una vez mi testimonio personal -más amistoso que académico- ante muchos jóvenes estudiantes de teología o candidatos al sacerdocio, cuando se les planteaba la hora de la decisión última: pedir o no pedir las órdenes, y por qué.

2) La actual crisis del laicado que no es sino el reverso de la anterior, y que el pasado sínodo ha vuelto a poner sobre el tapete. En realidad, el laicado es una noción totalmente correlativa a la de clero. Y los vaivenes de éste repercuten necesariamente en la definición de la identidad de aquél.

Por otro lado, es más que probable que la Iglesia esté llegando a eso que se ha llamado "la hora de los laicos," pero lambién que pasemos estérilmente por esa hora, por no habernos enterado de que había llegado ni de cn qué consistía.

3) $Y$, finalmente, una preocupación personal (pero creo que también muy compartida) sobre el modo de presencia de la Iglesia en el mundo. Liquidada sin retomo la cristiandad, no existe aún modelo acabado con que sustituirla, y ello lleva a muchos hombres a intentar un restauracionismo de la cristiandad, que se hacen seguramente con voluntad de servicio a la Iglesia pero que, en mi opinión, pueden causarle un daño histórico casi irreparable.

Pues bien, en este contexto se me ha ido haciendo convicción personal la idea de que hay siempre un paralelismo tácito entre la forma de relación entre ministro y fieles, al interior de la Iglesia, y la forma de relación exterior de la Iglesia con el mundo. Una Iglesia que en su estructuración interna sea clerical, tendrá pretensiones clericales al presentarse en la historia de la humanidad. Si la relación ministerio-comunidad es una relación de dominio y autoritaria, la Iglesia se presentará ante el mundo con pretensiones de dominio y de autoridad exterior. Si se hace consistir el ministerio en la distancia respecto de los fieles, la Iglesia intentará también distanciarse del mundo y de sus tareas en lugar de cristificarlas... etc., etc. Este paralelismo no queda desarrollado en el artículo (el cual ha querido ser más que nada de atención a los datos de las fuentes), pero sí que aparecen en él suficientes elementos para iluminarlo.

Y, por último, una confesión personal antes de entrar en materia. Me mueve a escribir este artículo una convicción últimamente optimista. A pesar del doloroso -y tantas veces traído- "inviemo eclesial" (K. Rahner), a pesar de lo duro de nuestra hora, sigo creyendo en las posibilidades creadoras que le dan a la Iglesia sus mismas fuentes - a las cuales se remile- y el hecho cristiano - del que esas fuentes testifican. Dios no ha querido poner corlapisas inútiles a su Iglesia, sino abrirla creadoramente a la misión que El le ha confiado, y que constiluye su razón de ser. Y sigo creyendo que el cristianismo liene aún un servicio que prestar y 
una palabra que decir a los hombres, con tal que la Iglesia se decida a pagar el precio necesario para poder decir esa Palabra: a vivir para esa misión que la convoca, y no para sus propios intereses institucionales. Por eso la experiencia del ministerio eclesial puede ser todavía positiva y motivadora.

De acuerdo con lo dicho, el trabajo va a tener tres partes: el hecho cristiano, el testimonio de ese hecho en el Nuevo Testamento y la vivencia de ese hecho a lo largo de la historia (sobre todo de los primeros siglos). O con otras palabras, la cristología del ministerio, la teología bíblica del ministerio, y la configuración del ministerio a lo largo de una historia que es siempre mayoritariamente entropica y minoritariamente creativa. Muchas otras cuestiones (algunas aparentemente más "actuales" por más particulares) quedarán fuera de este tratamiento expreso. Pero no creo que queden intocadas por él.

\section{El sacerdocio de Jesús y el no-sacerdocio de los sacerdotes}

El punto de partida para clialquier reflexión sobre el ministerio eclesial no ha de ser ni siquiera la estructura de las comunidades neotestamentarias, sino algo todavía más cercano a la raíz: la teologla del sacerdocio de Jesucristo.

En efecto, esa teología hubo de formularse ya en la época del Nuevo Testamento, y en condiciones claramente polémicas. Después de una llamativa y cuidadosa ausencia de la palabra "sacerdote" en todo el Nuevo Testamento, aparcce la carta a los Hebreos reivindicando ese título, pero con estas condiciones: sólo para Jesús, y de una manera nueva, la cual supone el fin de todo sacerdocio.

Todos los datos parecen indicar que la carta a los Hebreos está dirigida a unos cristianos, descontentos por lo que consideraban "excesiva secularidad" y falta de "esplendor cultural" del cristianismo. Es probable que esos destinatarios sean los cristianos de la comunidad de Roma, cuyos orígenes "judíos" (no paulinos) se consideran hoy como un dato suficientemente adquirido. En cualquier caso, se trata de unos cristianos decepcionados, que hoy tendrian algo de "lefebvrianos," y cuya situación de descontento los hacia antorar todo el aparato religioso-ritual del Antiguo Testamento. Pero el autor de la carta, lejos de transigir con esas demandas, explica a sus destinatarios: que todo aquel esplendor litúrgico veterotestamentario era pura sombra vacua; que lo que alli podía haber de buena voluntad o de buena intención, lo ha realizado Jesucristo de una manera no ritual sino existencial; y que a ellos mismos se les abre así la posibilidad de un culto "nuevo," que consiste no en la ofrenda de dones aparatosos, sino en la entrega de sus vidas.

Se hace necesario, por tanto, exponer un poco más detenidamente la sistematización teológica ( 0 , al menos, el esquema de ella) con que presenta esas conclusiones el autor de Hebreos. Y a ello vamos a dedicar esta primera parte de nuesuro estudio. Los estudios de Albert Vanhoye - como ya es sabido-constituyen aquí un punto de referencia obligado y una palabra casi definitiva sobre el tema. Los tenemos muy presentes aunque, para evitar acumulaciones de citas, rehuyamos las referencias constantes. ${ }^{1}$ 


\section{La encarnación de Dios, punto final de todo sacerdocio "religio- so" y veterotestamentario}

Sintetizando lo más posible, cabe decir que el sacerdocio, como fenómeno religioso y veterotestamentario, puede ser descrito con estos cuatro rasgos: (a) una consagración ritual a Dios; (b) la cual hacla al consagrado participante de la santidad divina; (c) y, por ello, lo capacitaba para aplacar a Dios con sacrificios, e impetrar de Dios bendiciones para los hombres. (d) Y, de este modo, le daba un "poder" especial, que lo separaba de los no sacerdotes, y servía para transparentarles a éstos la Divinidad ${ }^{2}$. Ese poder ante Dios reperculía, por tanto, en un poder ante los hombres.

La historia muestra cómo ese poder ante los hombres se protege y se salvaguarda después mediante mil instituciones humanas religiosamente justificadas: la "casta" o familia sacerdotal (la tribu de Levin), los sistemas de intransferibilidad que aseguran que no pueda cualquiera apropiarse de ese honor sino sólo aquel que es "elegido" por la divinidad, elc. Estas instituciones son lógicas no sólo por un posible anhelo de pureza religiosa, sino también porque, de hecho, el tipo de poder sacerdotal que hemos descrito, comporta en todas partes una serie de ventajas maseriales. Pablo reconoce el derecho de los ministros veterotestamentarios a "vivir del altar" (1 Cor 9,13). Aristóteles afirma que la metafísica pudo nacer en Egipto porque allí los sacerdotes tenían la vida suficientemente cubierta. Y en otro contexto, el que visite las pirámides de Teotihuacán, en México, hallará que las ruinas mejor conservadas son las de las viviendas de los sacerdotes (las más cercanas a la pirámide), precisamente porque constituían las construcciones mejores...

Y tras hacer esta descripción deberíamos affadir, como breve comentario, que aún hoy, infinidad de cristianos identificarian a sus presbíteros con una caracterización como ésa. Ello no deja de ser preocupante: quiere decir que las apariencias del ministerio eclesial suenan de hecho a Antiguo Testamento más que a evangelio. Y que, aunque luego los teólogos expliquen que "no es eso," tal explicación permanece incomprendida o secuestrada en los ámbitos académicos, y pesa ante los fieles mucho menos que las "apariencias" de la vida eclesiáslica de hoy.

El mensaje del Nuevo Testamento es precisamente que esos cuatro datos que acabamos de enumerar son los que quedan superados por la Encarnación de Dios en Jesús. Y por eso son esos cuatro datos los que el autor de Hebreos trata de destruir sistemáticamente a lo largo de su escrito. Veamos cómo:

Tomemos los dos primeros. Para comenzar, una consagración ritual nunca acerca a Dios, ni reviste al consagrado de la santidad divina. Es éste un vano intento de disponer de Dios, de "atravesar los cielos" o de ponerse "a la derecha" misma de Dios. Un intento tan vano como el de la torre de Babel, y que sólo es sombra y apariencia. Y la prueba de la vanidad de semejante empeflo es, para el istor de la carta, la debilidad humana que sigue rodeando a esos mediadores pre- 
suntamente tocados por la santidad ontológica de Dios. En este punto Hebreos posee la misma doctrina que 1 Timoteo 2,5 cuando afirma que no puede haber más que "un único mediador entre Dios y los hombres," Jesús, y califica a este mediador como "anthropos-Xristos." Es decir. Jesús puede representar a todos los hombres ante Dios porque comparte con ellos su misma naturaleza humana (cfr. Heb 2,14 y también Gal 3,19-20). Pero puede representar a Dios ante los hombres porque estŕ ungido con la plenitud de la divinidad (cfr. Heb 1,3, pero también Col $2,9)$. Y no hay otra posible mediación porque no hay tal poder del hombre ante Dios: es Dios quien "desciende" y Su Espíitu quien nos hace "llegar hasta El." Y llegar hasta El no con dones nuestros sino mediante el don suyo de entregar nuestras vidas (cfr. Heb 8,8-11 y 10,16). Esta es la imporancia y la profundidad de aquella tesis de la teología tradicional, de que en Jesús, el sacerdote era a la vez victima.

Por eso mismo, tomando ahora el tercer dato, las ofrendas del sacerdocio antiguo tampoco llegaban hasta Díos, ni menos aún le, agtadaban, le satisfacían o cambiaban su disposición para con los hombres. Por eso les ocurre lo mismo que a la ley: a pesar de su "bondad" han acabado por converirse en pura práctica impotente, supersticiosa y (en el peor de los casos incluso) mágica. La prueba de esto, para el autor de Hebreos, es que esos sacerdotes siempre habían de estar repitiendo sus ofrendas inútiles. Y la razón de ello es que Dios, por su santidad y su trascendencia, no se aplaca ni se complace en la sangre de animales, ni en el esplendor de vestimentas ni en la minuciosidad de reglamentos ceremoniales. Si algo humano puede agradar a Dios habrá de ser aquello humano que sea don de Dios mismo al hombre. Y esto no son los rituales ni las ceremonias, sino el corazón nuevo del hombre. Lo ritual sólo recobra sus aspectos positivos como efecto o expresión de ese corazón nuevo; nunca como causa o sustitutivo de el.

Y el lugar donde ese corazón nuevo actuó y se manifestó ha sido precisamente en la muerte de Jesús. Algo que era lo más contrario que podría imaginarse a un sacrificio ritual: ni tuvo ritos de ofrenda, ni ocurrió en lugar sagrado, sino "fuera." Y que fue además, "castigo legal" de un presunto delincuente religioso. Todo eso, naturalmente, mirando esa muerte con ojos humanos. Pero mirada con los ojos de Dios era el acto de tolal entrega de una vida, de ofrenda de sí mismo hecha posible por el mismo Espíritu Eterno de Dios (cfr. Heb 9,14), cuyo ser es la entrega.

Precisamente por eso, pasando al cuarto dato, esta forma de sacerdocio no da al mediador absolutamente ningún poder que le permita separarse de los demás. El mediador ya no es alguien que está "a milad de camino entre los dos," semidivino sólo, pero también sobrehumano. Sino al contrario: porque su esencia es la entrega de sf, lo lleva a "asimilarse en todo a sus hermanos" (Heb 2,14) hecho igual a ellos "en todo menos en el pecado" $(4,15)$. Ahí es donde reside esa buscada santidad del sacerdote que, de algún modo, transparenta a la divinidad: en la asimilación (o en la "encarnación") y, a partir de ella, en la común-(un)ión en 
lugar de la separación (cfr, Heb 2,17 a 5,10).

Añadamos, como conclusión que brota de lo anterior, la siguiente rápida reflexión: todo empeño por superar la actual crisis del ministerio mediante un proyecto de "clericalización," es decir, mediante un proyecto de separación (en el lílulo, en el status social, en el vestido... o en cualesquiera de esas cosas que no son "el pecado" según decía Heb 4,15) es un intento que no resolvera la actual crisis del ministerio, sino que aumentará esa sensación de pura "falsedad o sombra de las realidades verdaderas" que denunciaba el autor de Hebreos. Ello podría volver a la Iglesia más ghetto, pero menos Iglesia, más comunidad de carácter esenio, pero menos comunidad de Jesús, más organización de la superstición del hombre, pero menos institución de la encarnación de Dios. Es bien claro que "el hábito no hace al monje" y, en este sentido, es algo indiferente. Pero sí que puede configurar su stotus social y, en este sentido, hay que procurar que todo este conjunto de caracterizaciones extemas no se conviertan, en la Iglesia de hoy, en aquellas"persuasivas palabras del saber humano" a las que Pablo renunciaba deliberadamente porque envuelven el mensaje y dispensan al oyente de encararse con la locura de la predicación de la cruz (cfr. 1 Cor 1). Por eso mismo, tampoco cabe argitir que la renuncia a ese staisus exterior por parte de los ministros de la Iglesia equivale siempre y en toda circunstancia a un "avergonzarse de Cristo." Hay siluaciones en las que puede equivaler a un avergonzarse de poner la identidad con Cristo precisamente en la distancia respecto de los maltratados y de los privados de reconocimiento social.

\section{El "laico" Jesucristo, único sacerdote}

Esa es, a grandes rasgos, la sistematización que hace el autor de Hebreos, para combatir la concepción religiosa y veterotestamentaria del sacerdocio. Pero a partir de esta misma concepción, el autor de la carta se atreve además a recuperar para Jesús el título de sacerdote. Lo recupera, pero con estas características que vamos a enumerar ahora.

En primer lugar, subrayando el carácter "laico" que, por naturaleza, correspondía a Jesús frente a la casta sacerdotal: "aquél a quien aluden estas cosas pertenece a una tribu distinta, de la que nadie se ha dedicado al altar. Pues es bien patente que nuestro Señor ha salido de la tribu de Judá, a la cual nunca aludió Moisés al hablar de sacerdotes" $(7,13.14)$. El sacerdocio de Jesús consistió en una determinada manera creyente de vivir su existencia humana, su existencia "laica." No, por supuesto, en esa laicidad sin más; pero sl en una manera de vivirla. No puede pues la Iglesia buscar la identidad del sacerdocio en un apartamiento ritualista de esa laicidad, sino en su conversión hacia la entrega de la vida.

En segundo lugar, encontrando en las mismas páginas de la Biblia la figura extraña de "otro" sacerdote - Melquisedec-, la falta de información sobre él la convierte nuestro autor en señal de trascendencia, y la utiliza así para establecer 
el principio de que "existe un sacerdocio de otra clase" (cf. 7,11), de otro tipo. Y ello le permite proclamar tranquilamente "la abolición de la institución anterior, a causa de su impotencia e ineficacia" $(7,18)$. Jesús podrá asi ser llamado sacerdote, pero "de otro tipo:" "según el orden de Melquisedec" $(5,10$ y 6,20$)$.

Y finalmente, reservando ese nuevo título de sacerdote para sólo Jesús, y nunca para los dirigentes de la comunidad. De esta manera el sacerdocio de Jesús niega por un lado, el aspecto "cúltico" del antiguo, afirmando que no hay sacrificios que ofrecer, y que no hay más que conmemorar y celebrar una vida humana que, por ser vida entregada gracias al Espiritu, se ha convertido en único sacrificio agradable a Dios y en reconciliación de los hombres con el Padre. Pero además de eso, el sacerdocio de Jesús niega también el aspecto de "poder" del antiguo orden sacerdotal: la autoridad sólo puede ser servicio y Jesús ejerció la suya sólo desde ahí: por la fuerza de su verdad, y no por la dignidad de su título de escriba que no tuvo, o de su tílulo de sacerdote del que también careció. De manera parecida, ante el naciente ministerio de Pedro y Juan, los sacerdotes judíos se asombrarán de la fuerza de su palabra, porque eran gente del vulgo y sin tílulos (idiotai kai agrammatoi, cfr. Hech 4,13).

A partir de estos datos, será lógico también que aquello que parecía ser la tarea específica del sacerdocio, es decir, el sacrificio (thysia) cambie igualmente de significado para el autor de esta carta Nuestro autor tampoco descartara definitivamente ese concepto. Lo recuperará pero también "según un orden nuevo." Y, con esa capacidad alegorica de que hace gala, nos dejará abierta la puerta para relacionar ese orden nuevo con el "pan y el vino" (cfr. Gen 14,18, aludido en Heb 7,1). El autor, naturalmente, no fuerza su alegoria para que ese "pan y vino" no se entienda, otra vez, como mera ofrenda de dones exteriores. Pues lo que a él le interesa subrayar es que esos dones exteriores, y los sacrificios habituales, tradicionales, no agradan ni pueden agradar a Dios y, por eso, no le resuelven nada al hombre (cfr. 7,19ss). En cambio Jesús, en su nueva forma de sacerdocio, posee un nuevo tipo de sacrificio que es la entrega de st: no "la sangre de animales ni de machos cabrios, sino la suya propia" (Heb 9,12).

Prescindimos aquí de desarrollar, aunque si queremos insinuarlo, cómo a partir de esta última frase, puede recogerse la fómula del "pan y vino" que nuestro autor ofrecía tan discretamente en su alegoría. A partir de las alusiones a la entrega de $s[$ mismo, y de la propia sangre $(9,14$ y 12$)$, pan y vino dejan de ser meros dones exteriores y se convierten en los símbolos ancestrales de un modo de ser humano: compartir la necesidad (el pan) y comunicar la alegria (la copa). Cuando luego la Iglesia hable de ellos como "el cuerpo" y "la sange" de Jesús resucitado, no está aludiendo meramente a los componentes sólidos y líquido del cuerpo humano, sino a la persona (que eso significa el cuerpo para un semita) y a la vido (que eso significa la sangre para un semita) del Seffor Jesús. La persona y la vida de Jesrís son la necesidad humana compartida y la alegría comunicada a los hombres. Y por eso Dios se hace real- 
mente presente ahi, $y$ la Iglesia ha tenido un fino instinto creyente en todas sus defensas de la presencia real eucaristica, aun en epocas en que quizá no tenía ni siquiera calegorías filosoficas suficientes para expresar esa presencia Aquí se ve también la profundidad de la tesis clásica, antes evocada, de que, en este tipo de acerdocio y de sacrificio, Jesús es a la vez sacerdote, victima y altar. ¡Para el sacerdocio levítico o religioso eso supondría una contradicción! Pero con esa contradicción aparente se pore de relieve la destrucción del concepto habitual de sacerdocio.

Y bien, precisamente por esto, el autor de Hebreos será coherente con su modo de concebir, y exhortará a los creyentes -en la pequefla sección práctica con que concluye su discurso- a que "nadie se olvide de los sacrificios (thysial) que agradan a Dios y que son hacer el bien y hacer comunidad" (Heb 13,16). El culto ha sido trasplantado para un cristiano -y gracias a Cristo- de lo ritual a una determinada manera de vivir lo existencial (compárese Heb 13,16 con 7,27). $Y$ el autor avisa a sus oyentes de que esto debe permanecer, incluso aunque les suponga "ser echados fuera del campamento rargando con el oprobio de Jesús" $(c f r .13,13)$.

Como se ve, ha cambiado totalmente el sentido de la palabra thysia. Y solo este cambio permite su recuperación. Pues esta palabra, que en el Antiguo Testamento aparece más de cuatrocientas veces, en los evangelios sólo la encontramos dos veces en labios de Jesús: y ambas para desautorizarla (cfr. Mt 9,13 y $12,17)^{3}$. Pero la teologia del autor de Hebreos no ha sido infiel a Jesús: simplemente ha sabido mostrar (al igual que hara el evangelista Mateo con la ley) ${ }^{4}$ que aquella desautorización hecha por Jesús no equivalía a "derogar el sacrificio, sino a cumplirlo realmente." Es más bien el Antiguo Testamento el que - sin Jesís- se deroga a si mismo, porque "no ha sabido consumar nada" (Heb 7,19)5. Para expresar esta superación del Antiguo Testamento, el Nuevo recurrirá al adjetivo amomos (sin defecto) que seguin el ritual judio habia de caracterizar al cordero6. ofrenda sin mancha no hay otra que la vida para los demás, la vida entregada; y ese tipo de ofrenda es absolutamente imposible para el hombre? ${ }^{7}$. Este detalle es el que nos va permitir ahora decir una última palabra sobre la relación de la carta a los Hebreos con el resto del Nuevo Testamento. Pues, luego de todo lo dicho, podría surgir la pregunta de si el autor de Hebreos, con su recuperación del sacerdocio para aplicarlo a Jesús, no se ha apartado del resto del testimonio neotestamentario.

3. Un sacerdocio nuevo, único e irrepetible, que es la verdadera realidad de todas las antiguas sombras

A pesar de la clara diferencia de lenguajes, Hebreos, en el fondo, no ha contradicho al resto del Nuevo Testamento con su hábil recuperación del título de sacerdote. Más bien ha aclarado las cosas desde planteamientos que quizá antes no habian estado asi de explicitos y asi de hirientes. Hablando de Jesús, Pablo 
prefiere repelir la expresión más laica de que "se entregó." Pero Ef 5,2 llama a la entrega de Cristo "don y sacrificio" (prosfora kai thysia). Y a partir de ahi, Pablo puede exhortar a los cristianos a que conviertan sus personas (ino otros dones exteriores!) en un "sacrificio santo" (cfr. Rom 12,1 donde hagios puede equivaler al amomos de la expresión consagrada). Y Pablo considerará su propia entrega a la tarea apostólica como "sacrificio y liturgia" (thysia kai leitowgia: Fil 2,17) o incluso, al acusar recibo de un regalo de los filipenses, se atreverá a llamarlo con una de sus efusiones afectivas "sacrificio agradable a Dios" $(4,18)$.

Estos pocos textos son, sin embargo, suficientes para afimar que Pablo y Hebreos coinciden en la concepción existencial de lo que (a partir de la entrega de Cristo) ha pasado a ser el antiguo sacrificio ritual. Difieren sólo en que Pablo por esa misma razón, no da el título de sacerdote a ese Jesús que se entrega. Mientras que Hebreos, también por esa misma razón, sí se lo da Hebreos pues "sacerdotaliza" lo que ya Pablo habia calificado como entrega sacrificial. El lenguaje sacro se recupera ahora plenamente para lo existencial, pero sin que sea ya posible volver a contraponer lo "sacro" y lo "existencial."

Y, en absoluta coherencia con todo este planteamiento, se encuentran los dos datos siguientes del Nuevo Testamento que, a la luz de lo anterior, recobran ahora todo su significado y toda su profundidad.

En primer lugar, deliberadaniente, el Nuevo Testamento evita siempre llamar sacerdotes (o vocablos derivados del hiereys griego o del kohen hebreo) a los dirigentes cristianos, comenzando por los mismos apostoles. No sin dificultades, pero con absoluta decisión, el Nuevo Testamento crea aquí de la nada todo un léxico nuevo, tomado del modo existencial "profano," y no del religioso-rimal: enviados (apostoloi), supervisores (episkopoi), servidores (diakonot), dirigentes (hegoumenoi) 0 , simplemente, "los que arriman el hombro" (kopiountes). ${ }^{8}$ Todo este esfuerzo lingitístico muestra claramente dos cosas: que la Iglesia ha de tener y tuvo siempre sus dirigentes, pero que esos dirigentes no tienen que ver con el hecho religioso del "sacerdocio," sino con el hecho existencial de la vida entregada hasta morir, de Jesús. En todo caso, como vamos a ver, si hay algo "sacerdocal" en el Nuevo Testamento será la comunidad de vida que brota de Jesucristo.

En consonancia con esto, y éste es el segundo dato, el lengraje neotestamentario que nunca llama sacerdotal al grupo dirigente, llama en cambio sacerdotal a todo el grupo de creyentes o de seguidores de Jesús, porque, por el bautismo, están convocados a reproducir en sí mismos la vida-entregada de Jesús. Sólo ocurre esto en dos momentos del Nuevo Testamento. Hebreos no se había atrevido a hacerlo, quizá porque el material veterotestamentario que encontró para llamar sacerdote a Jesús había sido la figura individual de Melquisedec (personificada también en la alusión al rey del Salmo 110). Pero otros pasajes del Nuevo Testamento si que se atreven a hacerlo, porque encuentran pie para ello en la alusión del Exodo a un pueblo sacerdotal. Y así el Apocalipsis hablará dos veces de un reino de sacerdotes $(1,6$ y 5,10; cfr. también 20,6). Y la primera carta 
de Pedro, que procede probablemente de Roma, a donde quizás fue escrita la carta a los Hebreos como antes dijimos, mantiene una coherencia de lenguajes que parece ser pretendida y que, si Roma hubiese sido la destinataria de Hebreos, permitiría hablar de una lección bien aprendida La 1 Pedro llama sacerdotal al pueblo cristiano en cuanto "como piedras vivas se edifican" y de esta manera ofrecen a Dios, por Jesucristo, "el sacrificio (thysia) espiritual" ( $f f$. 1Pe 2,5.6). Pero, poco después, hablando y exhortando a los dirigentes de la comunidad entre quienes el mismo autor se incluye, no los llama para nada sacerdotes, sino simplemente "presbíteros" (1Pe 5,14). Es legítimo concluir por consiguiente que lo que hay de "sacerdotal" en la Iglesia no se basa en el ministerio eclesial (ni coincide con él), sino en la vida de Jesús comunicada al creyente. No olvidemos que los exegetas califican a la primera carta de Pedro como una exhortación bautismal.

Y si ahora echamos otra vez una ojeada a nuestro momento historico, hay que reconocer que, en este punto, el lenguaje eclesiástico de hoy configura todo un universo linguístico contrario al del Nuevo Testamento. A lo más, hoy se suele hablar de Jesucristo como "sumo" sacerdote, pero no como único sacerdote. Con ello hernos ido a parar a la concepción que ve el sacerdocio de Jesús no como algo nuevo y superador de los antiguos, sino como un caso particular más (si bien el más excelso) de un concepto universal de sacerdocio el cual, aún despues de Jesús, permanece intocado (y hasta confirmado). Con ello también, los demás usos de la palabra "sacerdote" han acabado por expresar, de hecho, "otras realizaciones de ese concepto universal, general de sacerdocio," más que la posibilidad de participar en la vida entregada de Jesús, mediante la entrega de la propia vida del cristiano, hecha posible por el mismo Esplítu de Jesús.

$Y$, porque este es el inconsciente latente de nuestra Iglesia, resulta luego imposible recuperar el llamado "sacerdocio de los fieles," y su fundementación bautismal, a pesar de las exhortaciones bienintencionadas y de los empertos voluntaristas de hacerlo. Pero son exhortaciones inútiles, porque chocan con una mentalidad inconsciente contraria a la del Nuevo Testamento.

\section{El esquema cristiano: la més profunda fidelidad en la ruptura mís aparente}

Para terminar, permitaseme ampliar un poco mís algo que ya ha quedado insinuado, y que constibuye un punto importante de la toología de Hebreos. Al hacer toda su revolución, y al desautorizar con aquella radicalidad el hecho religioso del sacerdocio (incluso del sacerdocio veterotestamentario), el antor de Hebreos no cree ser infiel al Antiguo Testamento, sino más bien cumplirlo. Este es un dato decisivo de cualquier cristologfa: Jesús da cumplimiento al Antiguo Testamento en el seno de una aparente rupura con él9. La argumentacion de la 
carta a los Hebreos vuelve repetidas veces sobre este modo de concebir, mediante la contraposición entre tipo y antitipo, sombra y realidad verdadera, anuncio y cumplimiento, etc., etc. Pero, aún mejor que el léxico de la carta, formula esto mismo una frase feliz de A. Vanhoye: "el Antiguo Testamento como revelación, anuncia el fin del Antiguo Testamento como institución." 10 Estamos aqui en el meollo mismo del hecho de Jesucristo, de los tutulos que se le aplican cambiando su significado, y de su misión salvadora, que da vida pasando hasta el fondo por la muerte.

Será importante no olvidar nunca este principio porque luego, al pensir en nuestra situación actual, iremos viendo que ese principio tiene también una cierta aplicabilidad para la Iglesia. Aunque la Iglesia ya no es el Antiguo Testamento, tampoco es aún el cumplimiento absoluto de la promesa. Por eso, cabe decir también de ella que "la Iglesia como revelación anuncia (no su fin, pero si) su perpetua reforma como institución." Y esto habría de ser fundamental, no sólo para la problemática hodierna, sino, sobre todo, para la fidelidad plena - y no farisea- de la Iglesia al Dios de Jesucristo. También el pecado de la Iglesia puede asemejarse aqul al pecado de Israel: aferrarse a su propia materialidad, y no saber reconocer al Jesús que viene a darle cumplimiento, en un aparente destrozo de esa materialidad.

Este principio tan importante puede dar razón asimismo de la unidad dinåmica del Nuevo Testamento, en medio de su pluralidad constatada y que, ahora mismo, volveremos a palpar. Y así Pablo y Santiago pueden sonar a contrapuestos en sus formulaciones sobre Abraham o sobre la justificación por las obras. Pero lo curioso es cómo Mateo, partiendo desde un talante que podríamos llamar "santiaguista" (por la importancia de las obras), llega a posiciones de desautorización de la ley muy cercana a Pablo. Y cómo los escritos de Juan, partiendo desde un talante muy paulino (por antijudaico) llegan a posiciones muy "santiaguistas" de valoración de la ética. El Nuevo Testamento es la interacción de esas pluralidades y la totalidad de esas parcialidades.

\section{Transición a la segunda parte}

Una vez que hemos establecido con toda su radicalidad, la doctrina cristológica sobre el sacerdocio, debemos afrontar cierta objeción, que puede ser formulada así: la doctrina de la carta a los Hebreos, precisamente por su caracter polémico, es en exceso unilateral. Se la puede comparar a determinadas afirmaciones polémicas de Pablo sobre la "exclusividad" de la cruz, o la "exclusividad" de la fe, que luego el propio Pablo completa o matiza, con su misma conducta o en momentos menos polémicos.

En el caso de Hebreos, la unilateralidad consiste en una afimación no balanceada del carácter escatológico del hecho cristiano (ןel autor parecería pensar a veces que el pecado ya no es posible en la Iglesial). Ahora bien, el cristianismo no afirma solo el "ya sf" de la escatología, sino tambien su "todavia no." El pro- 
blema de la armonización de ambas afirmaciones es uno de los problemas teológicos fundamentales y, como ya comentamos en la cristología, puede autorizar cierta recuperación de las realidades pasadas, con tal de que esa recuperación no suponga una recarda.11

En esta situación de retraso de la escatologí, cabe decir que la inmediatez del hecho de Cristo puede necesitar otras aparentes mediaciones, no por falta de plenitud de la mediación cristológica, la cual ha empalmado definitivamente nuestra "came y sangre" (Heb 2,14) con los "cielos atravesados" y la sesión a la diestra del Padre (Heb 8,1), sino por faita de capacidad de los hombres para captar esa plenitud, desde la dimensión de su historia temporal concreta.

Dicho de modo más sencillo, o quizás más psicológico, aun después de Jesucristo la gente necesita testigos, y tenderá a sacralizarlos: a convertirlos en "puentes ontológicos" entre Dios y los hombres y, por tanto, en "sacerdotes" según el significado antiguo. La gente necesita expresiones exteriores, solemnes, ceremoniosas, y tenderá a magnificarlas. Sólo importa comprender que ésa es una necesidad del psiquismo humano y no una exigencia de la psicologia de Dios. Ella puede ser requerida por la pedagogía para con los hombres, pero no por el culto debido a Dios. Esta percepción clara es la que haria que la "recuperación" de las falsas mediaciones superadas no se convirtiera en una "recaída" en ellas, o un retomo al Antiguo Testamento. Ha de ser una recuperación que no vuelva a absolutizar esas pseudomediaciones, sino que sea plenamente consciente de su interinidad y de su provisionalidad.

Es mérito de la Iglesia a lo largo de su historia, haber captado esa necesidad de la situación de los hombres, y haber tenido la oportuna condescendencia pedagógica con ella Pero la condescendencia pedagógica se desvirtuaría si se convirtiera en claudicación, porque ello implicaría la recaida en el Antiguo Testamento y una evacuación tácita de Jesús. Este peligro ha amenazado muchas veces al catolicismo. Ast, por ejemplo, aún es posible recordar muchas lecturas "católicas" de Hebreos 5, 1ss. que tomaban este texto como una descripción del sacerdocio de Jesucristo, icuando en realidad es una descripción del tipo de sacerdocio anulado por Jesucristo! Curiosamente, lo cristológico era usado en esas lecturas como una sutil excusa para recaer en el Antiguo Testamento. Y, en esta misma línea, cabe también recordar esa discutible definición del cura como alter Christus, en la cual lo más curioso - y lo peligroso- es que lo de alter Christus amenazaba con funcionar como excusa para dispensar al ministro de intentar ser alter lesus: era la dignidad del resucitado más que la vida humana del Jesús histórico lo que parecía encarnar el cura. Esta ideología del alter "Christus" sin el alter "Iesus" ha sido una de las razones que más ha desvirtuado el ejercicio del ministerio eclesial, y una de las causas más serias de su crisis actual.12

Como ahora mismo vamos a ver, la Iglesia, por su realidad intrahistórica $-\mathbf{y}$ no meramente escatologica-, necesila ministerios. Los necesita porque Dios respeta siempre las leyes de la historia al encarnarse en ella. Pero ese ministerio 
eclesial no tiene una fundamentación inmediatamente teológica ni cristológica (esto atentaría contra la unicidad del único mediador y del sacerdocio único de Jesucristo), sino una fundamentación inmediatamente eclesiológica. A veces se quiere recuperar ese carácter inmediatamente cristológico (o "sacerdotal") para los ministros de la Iglesia, argumentando que todos los fieles son sacerdotes a la hora de poder dírigir su culto a Dios, pero el ministro lo es además para manifestar la presencia activa de Cristo mediador (es decir, de Cristo sacerdote) en la vida de los creyentes. Pero a eso hay que responder que manifestar la presencia activa de Cristo mediador sólo podrá hacerlo el ministro eclesial destruyendo su propia pretensión mediadora y sacerdotal (pues en eso consiste la mediación de Jesucristo). De no ser ast, esa pretendida manifestación se convertirá insensiblemente en sustirucion. También ha de haber en la comunidad cristiana alguien que haga presente el sefiorio único del Padre y de Jesís (cfr. 1 Cor 8,6), lo cual es un rasgo fundamental y constiutivo de la comunidad: pues la comunidad de fe ya no es dueth - de- si, no es "dembcrata," sino obediente. Pero esa presencia activa del único Sefhor solo podrá hacerla presente el ministro destruyendo su propio nombre de Señor, o su propia autoridad, y no haciéndose llamar "padre" (efr. Mt 23, 7 11). De ahr la tendencia del Nuevo Testamento a evitar no sólo el término concreto de "sacerdote," sino otros como los de jerarquía o potestad (eksousia), para los responsables de la Iglesia. Pues de lo contrario, otra vez, con la excusa de manifestar, suplantaria. $Y$ de hecho, esto es lo que ocurrió no pocas veces en el pasado reciente: el sacerdote era sacerdote por medio de Cristo, sin duda pero además de Cristo: las gentes lo veian como representante de Dios, etc. Y por eso se le separaba de la gente, siendo asi que la función mediadora de Jesucristo se realiza en su "asimilación total" a sus hermanos. Por eso, si se quiere hablar de una visibilización de la presencia de Cristo en la vida de los creyentes, yo prefiero hacerlo con el lenguaje. neocestamentario de la reconciliacion: "Dios en Cristo nos reconcilió con El, y nos confí el servicio de la reconciliación" (2Cor $5,18 s s)$. El ministerio eclesial es un servicio de reconciliación que encarna la reconciliación del mundo con Dios. Es una tarea creadora de comunión y de comunidad, que reflejen la comunión del mundo con Dios.

O con otras palabras, el ministro eclesial no es ya simplemente, o por su mismo status, un hombre "de Dios" o un alter Christus, sino que es un "hombre para la comunidad" creyente y, precisamente por eso y a traves de eso, hombre de Dios e initador de Jesucristo.

De acuerdo con esto, la tesis de este trabajo serí que, el momento historico actual parece exigir - y permite- una superación de esa "recarda en el Antiguo Testamento," sin ir a dar por otro lado en un escatologismo comunitario, imposible por unilateral. Pero para delimilar las posibilidades de recuperación del hecho cristologico, se nos hace necesario estudiar ahora un poco más los testimonios del mismo Nuevo Testamento y de la vida misma de la Iglesia. O con otras palabras, es preciso estudiar un poco si lo que el Nuevo Testamento y la tradición permiten y exigen a la Iglesia está en consonancia con ese que parece ser imperativo 
de nuestra hora histórica. (Continuará)

\section{NOTAS}

1. He ulilizado sobre todo: Situation du Christ, Paris, 1969. Sacerdotes antiguos, sacerdote nuevo según el Nuevo Testamento, Salamanca, 1984. Más los apuntes académicos: Tettus de sacerdotio Christi (Roma, 1969); De Epistola ad Hebraeos Sectio Centralis (Roma, 1966). Puede verse tambien: J. Smith. A priest for ever. London, 1969. B. Klappert, Die Escatologie des Hebraeerbriefes, München, 1969.

2. Quizá convenga notar que este sistema de "separaciones" tiene su lógica inmanente: la santidad de Dios consiste en su lejanía de nosotros mucho más que en su misericordia Y, desde este presupuesto, la experiencia religiosa de que Dios es santo y el hombre pecador, lleva a la conclusión de que sólo "separándose" de los hombres es posible acercarse a Dios sin morir. De ahí las innumerables "leyes de pureza" del Antiguo Testamento.

3. Desvalorizada aparece también en Mc 12,33. Pero ahora no está en labios de Jesús, sino del escriba que le preguntaba, y como consecuencia de la enseñarza dada por Jesús en su respuesta.

4. Cfr. Mt 5,17.

5. Consumar, llevar a perfección. divinizar... traducen la célebre teleiosis que expresa la perfección ontológica de Dios. Deliberadamente he rehuido citar aquí los texios en que aparece, dada la imposibilidad de una traducción satisfactoria. Pero es preciso recordar, siquiera sea en una nota, que con esta palabra es como mejor se expresa esa presunta "divinidad ontológica" que no tuvieron los sacerdotes ni los riமs antiguos. Y que, según Varhoye, la teleiosis traduce precisamente la expresión "llenar las manos" (mille-yad) con que se designaba la consagración sacerdotal en el Antiguo Testamento. He expuesto esto mismo en La humanidad nueva, (6a. edición comegida), pp. 61-62 y 150-152.

6 Se lo encuentra en Ex 29,1 y en Lev 1,3.10; 4,3; 5,15; Ezeq 43,22... Lo curioso de esta palabra es que, traduciendo un vocablo hebreo que designa más bien la pureza moral y religiosa (samim), los LXX la han empleado sobre todo para la ofrenda cúbtica. Como si expresaran así le búsqueda de un camino (fallido) para la imposible pureza del hombre ante Dios.

7. La aplican a la obra de Jesucristo Heb 9,14 ("se ofrecí a sf mismo, sin mácula") y $1 \mathrm{Pe} 1,19$ ("el cordero sin mancha Cristo"). A partir de Jesucristo, 2Pe 3,14 se atreverá a proponerla como programa a los cristianos. Y lo mismo hará el corpus paulino (Ef 1,4; Fil 2,15; Col 1,22) siempre como obra de Crisw o de Dios.

8. La orientación de ese lenguaje la muestra bien Heb 12,15 donde se califica como "episeopal" la natural preocupación o responsabilidad de todo cristiano por la comunidad.

9. Véase por ejernplo lo que digo sobre el mesianismo de Jesús en La hwnanidad nueva, pp. 252-257: Jesús es el esperado que destruye las esperanzas.

10. Sacerdotes antiguos, sacerdote nuevo... (cir), p. 197.

11. Ver La humanidad nueva, pp. 150-151.

12. Hago esta afirmación sobre todo a nivel estructural, y sin entrar en los niveles personales donde -evidentemente- pudo darse y se dio una gran santidad en la manera como muchos curas ejercieron su ministerio. 